\title{
Biomarkers status and their relation with the presence of type 2 diabetes with and without angiopathy
}

\author{
Conference Paper · May 2017
}

DOI: 10.1530/endoabs.49.EP562

CITATIONS

0

19 authors, including:

\section{Manuel Bicho}

University of Lisbon

282 PUBLICATIONS 687 CITATIONS

SEE PROFILE

\section{Joao Raposo}

New University of Lisbon

69 PUBLICATIONS 499 CITATIONS

SEE PROFILE
READS

23

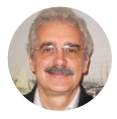

Rui Duarte

APDP

46 PUBLICATIONS 78 CITATIONS

SEE PROFILE

Some of the authors of this publication are also working on these related projects:

"Variações polimórficas de enzimas associadas à biodisponibilidade de homocisteína e de vitaminas (B2, B6, B12 e ácido fólico) cofactores do seu metabolismo em diabéticos tipo 2" View project

Dietary Intake in the third trimester of pregnancy related with nutritional status and chronic disease risk factors View project 


\section{Biomarkers status and their relation with the presence of type 2 diabetes with and without angiopathy}

\section{Ana Valentel,2,3, Manuel Bicho3,4, Rui Duarte5, Joä॰ F. Raposo5, Helena S. Costai,}

1 Research \& Development Unit, Department of Food and Nutrition, National Institute of Health Dr. Ricardo Jorge, I.P., Av. Padre Cruz, 1649-016 Lisbon, Portugal

2 Centro de investigação da Atlântica University Higher Institution, Fábrica da Pólvora de Barcarena, 2730-036, Barcarena, Portugal

${ }^{3}$ Laboratório de Genética, Instituto de Saúde Ambiental, Faculdade de Medicina da Universidade de Lisboa, Av. Prof. Egas Moniz, 1649-028 Lisboa, Portugal ${ }^{4}$ Instituto de Investigação Científica Bento da Rocha Cabral, Calçada Bento da Rocha Cabral, 14, 1250-047 Lisboa, Portugal ${ }^{5}$ Associação Protectora dos Diabéticos de Portugal, Rua do Salitre 118-120, 1250-203 Lisboa, Portugal

${ }^{6}$ REQUIMTE/LAQV, Faculdade de Farmácia da Universidade do Porto, R. Jorge Viterbo Ferreira 228, 4050-313 Porto, Portugal

\section{Introduction}

The knowledge on the status of several biomarkers [1] is a useful tool for disease clinical characterization and treatment of type 2 diabetes. The additive clinical effect of the presence of different biomarkers can be used to evaluate the risk to develop angiopathy and also in disease management.

\section{Aim}

The aim of this study was to evaluate the levels of cardiovascular, oxidative stress and nutritional biomarkers and their relationship with the presence of type 2 diabetes and angiopathy.

\section{Methods}

A population-based case-control study in 150 Portuguese type 2 diabetic patients was performed. Group I - 75 diabetics with angiopathy, group II - 75 diabetics without angiopathy and group III non-diabetic controls. Plasma levels of homocysteine, cysteine, malondialdehyde (MAD), vitamins $B_{6}, C, A$ and $E$ and carotenoids were measured by HPLC methods. Vitamin $B_{12}$ and folate serum levels were achieved by an electrochemiluminescence method.

\section{Results}

The baseline characteristics of diabetic patients studied are presented in Table 1. The results of biomarkers plasma or serum levels evaluation are presented in Table 2. The hyperhomocysteinemia prevalence was $20 \%$ (group I), $8.7 \%$ (group II) and $0.71 \%$ (group III). Group I showed the higher prevalence of hypercysteinemia (17\%). The MAD serum levels were above the reference value for all groups. The percentage of subjects with ascorbic acid low plasma levels were statistically different in diabetic (I: $55 \%$; II: $47 \%$ ) compared to non-diabetic subjects (III: $22 \%$ ). The prevalence of hypovitaminosis $\mathrm{B}_{6}$ deficiency was at least $30 \%$ for all groups. Type 2 diabetes predisposes to hypovitaminosis $\mathrm{C}(\mathrm{OR}: 3.10 ; p=0.0002)($ Table 3$)$. In group I, the probability to have hyperhomocysteinemia was around 3 times higher $(p=0.04)$ in comparison with group II and 35 times $(p=0.0006)$ with group III (Table 4). The combined effect of type 2 diabetes and angiopathy is associated with high MAD (OR: $5.33 ; p=0.002)$ serum levels compared to group III (Table 5). The effect of the angiopathy presence was only significant for homocysteine biomarker (Table 5).

Table 1 - Baseline characteristics of the study population.
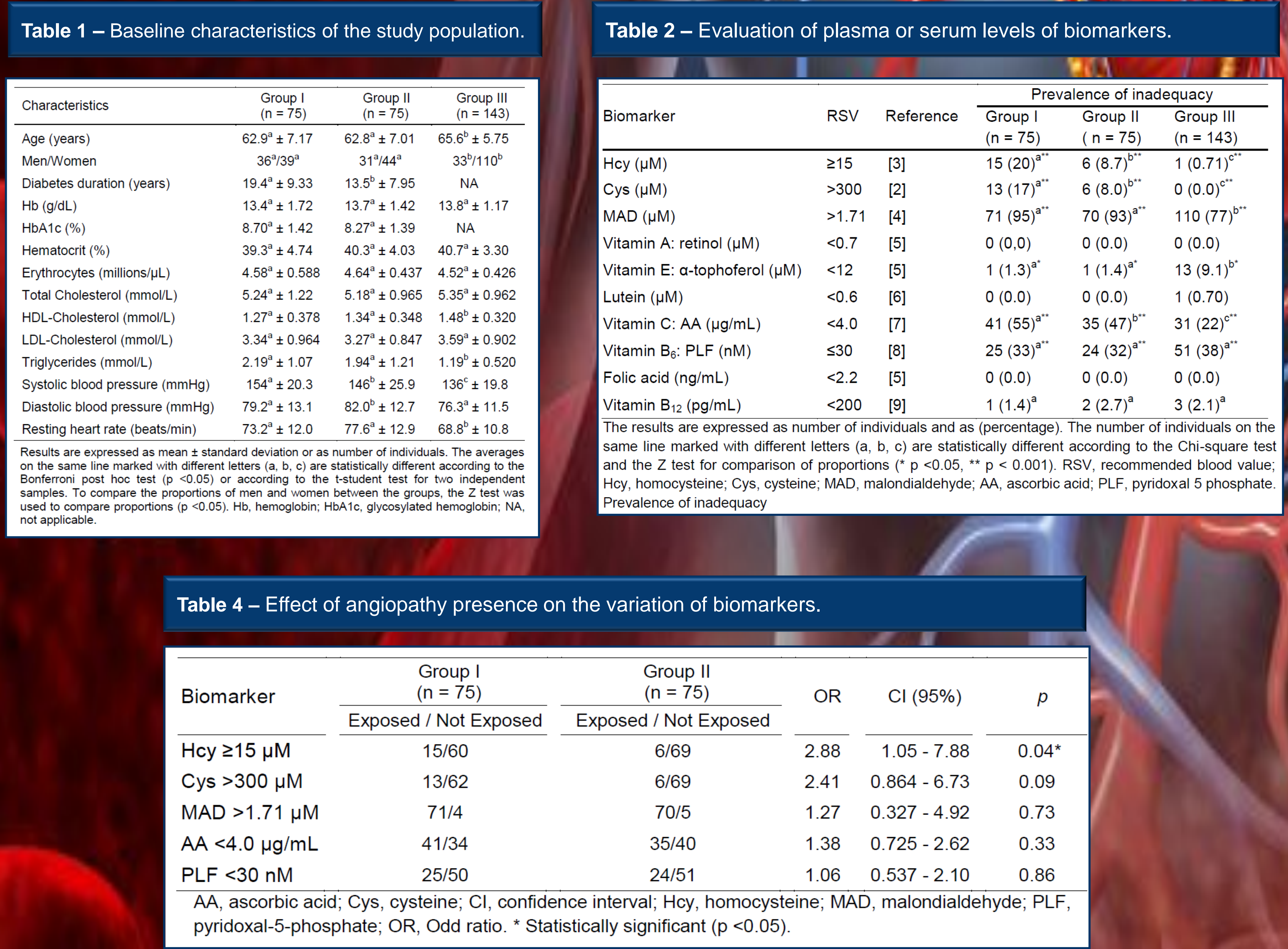

Table 3 - Effect of type 2 diabetes presence on the variation of biomarkers.

\begin{tabular}{|c|c|c|c|c|c|}
\hline \multirow[t]{2}{*}{ Biomarker } & $\begin{array}{l}\text { Group II } \\
(\mathrm{n}=75)\end{array}$ & $\begin{array}{l}\text { Group III } \\
(n=143)\end{array}$ & \multirow[t]{2}{*}{ OR } & \multirow[t]{2}{*}{$\mathrm{Cl}(95 \%)$} & \multirow[t]{2}{*}{$p$} \\
\hline & Exposed / Not Exposed & Exposed / Not Exposed & & & \\
\hline Hcy $\geq 15 \mu \mathrm{M}$ & $6 / 69$ & $1 / 141$ & 12.3 & $1.45-104$ & $0.02^{*}$ \\
\hline Cys $>300 \mu \mathrm{M}$ & $6 / 69$ & $0 / 143$ & NA & NA & NA \\
\hline$M A D>1.71 \mu \mathrm{M}$ & $70 / 5$ & $110 / 33$ & 4.20 & $1.57-11.3$ & $0.004^{* *}$ \\
\hline AA $<4.0 \mu \mathrm{g} / \mathrm{mL}$ & $35 / 40$ & $31 / 110$ & 3.10 & $1.70-5.68$ & $0.0002^{* *}$ \\
\hline$P L F<30 \mathrm{nM}$ & $24 / 51$ & $51 / 85$ & 0.784 & $0.432-1.42$ & 0.425 \\
\hline
\end{tabular}

\section{Conclusion}

The prevalence of hypovitaminosis $B_{6}$ was relevant in all studied groups. Low levels of vitamin $C$ were more frequent in type 2 diabetics with angiopathy than without or non-diabetic subjects. The presence of type 2 diabetes increases the risk of hyperhomocysteinemia, oxidative stress and hypovitaminosis $\mathrm{C}$. The isolated effect of angiopathy increases the probability to have hyperhomocysteinemia. 